\title{
Neurology education: The role of assessment
}

Sir,

Lemon, et al. have brought to light a recurring theme in medical education - the unpopularity of neurology among medical students and their subsequent avoidance of the subject. ${ }^{[1]}$ The authors have clearly produced a resource that is popular among medical students and that has as its core objective the teaching of neurology as a practical subject. This approach is likely to be helpfulhowever, the authors also mention another deep-set problem that may have far reaching consequences for medical education in neurology.

That problem is the ability of students to study to the exam and thus to pass their exams overall without having 
to study neurology. This phenomenon affects not just neurology-almost any other subject that is perceived as being difficult can be adversely affected. The effect of assessment on medical education is extremely strong. Educators can change the syllabus or can reform the curriculum - but if they don't change the assessment in line with the other changes, then their reforms won't work. This is true for all types of assessment-from learning needs assessment to formative assessment to summative assessment. ${ }^{[2,3]}$ Medical students realize that they have got into medical school by passing exams and that they will only progress through medical school and graduate by passing exams. The remedy to this problem is relatively simple to state but perhaps more difficult to implement. The remedy lies in ensuring that students cannot pass an exam overall without passing all of the core subjects within it. And neurology must be one such core subject. Neurology is a key to the practice of medicine-medical students simply should not be allowed to graduate without achieving a basic standard in it. The difficulty in implementing this solution lies in the fact that all specialties will want to argue that their subject is core and so must be a core part of exams. The answer to this problem in turn is likely to lie in cooperation rather than competition. Neurologists can reach out to colleagues in other specialties and explain how neurology is a vital part of the preclinical sciences (such as anatomy) and the clinical sciences (such as stroke medicine or psychiatry). By integrating neurology into other important subjects, neurology should receive reciprocal support in return.

Kieran Walsh

BMJ Learning, BMJ, BMJ Group, Tavistock Square, London, UK

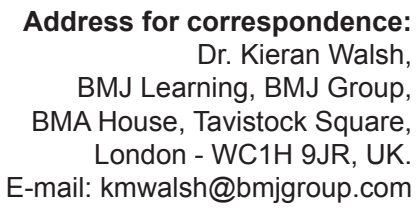

\section{References}

1. Lemon TI, Davies D. Accessible knowledge for tomorrow's surgeons and doctors. J Neurosci Rural Pract 2014;5:323-4.

2. Walsh K. How to assess your learning needs. J R Soc Med 2006;99:29-31.

3. Miller GE. The assessment of clinical skills/competence/performance. Acad Med 1990;65 Suppl 9:S63-7.

\begin{tabular}{|l|l|}
\hline \multicolumn{2}{|c|}{ Access this article online } \\
\hline Quick Response Code: & Website: \\
\hline & www.ruralneuropractice.com \\
\cline { 2 - 2 } & \\
\hline
\end{tabular}

